\title{
Argumentation and Persistent Disagreement
}

\author{
Diego Castro
}

Faculty of Philosophy

University of Groningen

Oude Boteringestraat 52, 9712 GL Groningen

Netherlands

d.r.castro.amenabar@rug.nl

\begin{abstract}
Some disagreements seem to be persistent: they are, pretty much, immune to persuasive argumentation. If that is the case, how can they be overcome? Can argumentation help us? I propose that to overcome persistent disagreements through argumentation, we need a dynamic and pluralistic version of argumentation. Therefore, I propose that argumentation, more than a tool that uses persuasion to change the mind of the counterpart, is a toolbox that contains persuasion, deliberation, negotiation, and other dialogical strategies that can be used to reach an agreement.
\end{abstract}

Résumé: Certains désaccords semblent persistants: ils sont, à peu près, à l'abri de l'argumentation persuasive. Si tel est le cas: comment les surmonter? L'argumentation peut-elle nous aider? Je proposerai que, pour surmonter les désaccords persistants par l'argumentation, nous avons besoin d'une version dynamique et pluraliste de l'argumentation. Par conséquent, je proposerai que l'argumentation, plus qu'un outil qui utilise la persuasion pour changer l'esprit de la contrepartie, est une boîte à outils qui utilise la persuasion, la délibération, la négociation et d'autres stratégies de dialogue pour parvenir à un accord.

Keywords: deliberation, dialogue types, negotiation, persuasion, persistent disagreement, settlement.

\section{Introduction}

Disagreement is a common phenomenon. People disagree often and about diverse topics. And while sometimes we can deal with disagreement and reach agreement easily, on other occasions that is not the case. Compare the following examples: 


\section{Example 1: Plans for Saturday}

1.A. Gina and John have a picnic planned for next Saturday. Two days before, the following dialogue ensues:

(1) Gina: "John, I think we should cancel our picnic afternoon. There's rain expected."

(2) John: "I think we could go anyway, it's just some water."

(3) Gina: "Is not just some water, they're forecasting heavy rain."

(4) John: "Ok, you're right, maybe next time."

1.B. Gina and John have a party planned for next Saturday. Two days before, the following dialogue ensues:

(1) Gina: "John, I really don't want to invite Thomas to the party; you know how much I dislike his girlfriend."

(2) John: "But Thomas is one of my best friends! Is it so hard to tolerate his girlfriend for a couple of hours?"

(3) Gina: "Do you remember the insulting things she said to me last time?"

(4) John: "Yes, as I see it, they were not that bad!" (...)

While both of these dialogues can be considered argumentative exchanges from the same genre (a domestic dialogue), there is a big difference between them. In the first case, Gina has been able to provide a compelling argument to persuade John, but in the second case, persuasion does not occur and probably never will; we can imagine dialogue 1.B. going on and on without a proper resolution, even with an escalation of the disagreement, as is sometimes the case (Paglieri 2009). That does not mean there is no way around the disagreement in that example, only that persuasion might not be the best option. So, while the parties can resolve the issue in Example 1.A, it is unlikely that they can resolve it in 1.B. ${ }^{1}$

\footnotetext{
${ }^{1}$ By resolution, I mean "that the argumentative discourse has resulted in agreement between the parties involved on whether or not the standpoint at issue is acceptable" (van Eemeren et al. 2014, p. 528); that is, a disagreement will be resolved only if one of the parties succeeds in rationally persuading the other that their standpoint is acceptable.
} 
Cases like 1.A do not seem too challenging for argumentation theorists. If we disagree, and one of us can come up with a sound argument that will rationally persuade the other, there is not much else that needs to be said. In this paper, then, I want to focus on cases like 1.B. I will call such cases persistent disagreements (Elgin 2010). A persistent disagreement, as I define it, is a disagreement that likely cannot be resolved by persuasive argumentation. That is, even after full disclosure of their arguments, or at least their easily available arguments, the parties will likely continue disagreeing. This definition brings us to the main question of this paper: what can we do to rationally overcome persistent disagreements? By a disagreement that has been "overcome," I mean here any agreement that results from a dialogical exchange of reasons. Therefore, it is a broader concept than resolution, which is one kind of overcoming centered on persuasive argumentation.

As we will see, there are many things that the parties can do to overcome disagreements. In case 1.B, for instance, even if neither Gina nor John are persuaded by each other's arguments, they can still negotiate their way out of the disagreement, call a friend to mediate, or even agree to toss a coin.

Thus, the main thesis of this paper is the following: there are various ways to rationally overcome disagreements, and as long as the parties provide reasons, it is plausible to consider all of them as being covered by the term "argumentation." If that is the case, an argument should be considered as not only "a publicly expressed tool for persuasion" (Govier 1989, p. 177), but as any tool for rationally and dialectically overcoming disagreements.

This approach to argumentation, then, is pluralistic as opposed to monistic. Monistic approaches, like the pragma-dialectical approach to argumentation (van Eemeren and Grootendorst 2004), see all argumentation as containing resolution-oriented attempts at persuasion. ${ }^{2}$ In pluralistic approaches, on the other hand (see Blair 2012; Doury 2012; Goodwin 2007; Micheli 2012; Walton 1998), argumentation may have different specific functions: for instance,

\footnotetext{
${ }^{2}$ Some accounts, while monistic, do not consider persuasion to be the main goal of argumentation. For instance, the epistemic approach to argumentation claims that the goal of argumentation is "to yield knowledge or reasonable belief" (Biro and Siegel 2006, p. 192).
} 
to persuade, to obtain knowledge, to make a deal, to impress the audience, or even to deepen the disagreement.

Both approaches have advantages and disadvantages. Monistic approaches have two main advantages: first, they have a clear-cut definition of what is and what is not argumentation. For them, any dialogical move that attempts to achieve the main goal of argumentation should be regarded as an argumentative move, and if the move does not target that goal, it should not be considered an argumentative move. Second, monistic approaches set a normative standard, that is, they establish the conditions that would make an argument a good argument and evaluate real-life argumentation against those felicity conditions. In pragma-dialectics, for instance, the goal of argumentation is to convince a rational judge about the acceptability or unacceptability of a certain standpoint (van Eemeren and Grootendorst 1984). Arguments, then, could be evaluated as good or bad contributions towards that goal. The norms according to which the contributions must be oriented to the resolution of a disagreement have been specified with certain dialogue rules called "rules for critical discussion" (van Eemeren and Grootendorst 2004).

The risk of monistic approaches is that they may leave aside, or evaluate as wrong, some moves that fall under the colloquial term "argumentation" and that can help the parties overcome their disagreements based on reasons. For instance, when parties to a disagreement decide to shift from a persuasion dialogue to a negotiation dialogue, to examine whether a compromise is feasible after having discovered that a resolution is not, monistic approaches may tend to regard the reasoning within the negotiation dialogue as irrelevant from an argumentative perspective, or they might even classify the shift and the subsequent reasoning as "fallacious"(Godden and Casey 2020). As a result, monistic approaches could become more distanced from real-life argumentation. This risk increases when the parties deal with persistent disagreements.

Pluralistic approaches, on the other hand, give the parties different paths to overcome their disagreements and fulfil other goals. By characterizing more of these avenues as "argumentative," argumentation theory is better positioned to understand the simi- 
larities and differences between various kinds of attempts to rationally overcome disagreements and to develop criteria for their evaluation. Therefore, this approach seems better connected to actual argumentative practices and might provide a greater inventory of instruments with which to rationally overcome disagreements. We can think of monistic argumentation as a hammer, useful only with nails but not with screws, while pluralistic argumentation is a sort of toolbox.

The risk of pluralistic approaches is twofold. First, it is not so easy to know what is and what is not argumentation. For monistic approaches, one specific goal of argumentation provides that limit: any attempts at fulfilling the main goal should be considered argumentation, and only those. However, the limit is less clear for pluralistic approaches. Second, the evaluation of different argumentative moves is vaguer. Where monistic approaches are able to establish a clear-cut criterion for considering arguments as good or bad moves, in a pluralistic approach, it is harder to say when, for instance, a settlement process is a good or bad move.

However, looking at the issue from the problem of persistent disagreement, I consider that the advantages of pluralistic approaches outweigh their risks, and the risks are not insurmountable. This paper, then, will develop and deepen a pluralistic position that has been previously defended by Walton (1990; 1998). Besides developing different dialogue types that are relevant for the study of argumentation, he provides a more inclusive definition of "argumentation," according to which argumentation is a verbal means intended to "resolve, or at least contend with a conflict" (1990, p. 411). The expression "contend with" suggests that argumentation can help us overcome disagreements in ways that are not restricted to resolution.

In the spirit of Walton's approach, I suggest in this paper that argumentation, as a process, consists of providing reasons to overcome disagreements. This definition excludes processes where the parties do not provide reasons or provide reasons in situations where disagreements are not present. Reasons, here, should be understood as a certain type of inference, in which a premise is presented as providing a warrant to a conclusion (Mercier and Sperber 2011). As such, reasons are not an internal cognitive 
decision-making process but, rather, "are primarily for social consumption" (Mercier and Sperber, 2017, p. 127). ${ }^{3}$ As a result, parties are not said to be arguing when they overcome a disagreement through a fist fight (because they do not provide reasons) or when they provide reasons in situations where there is no disagreement, like in inquiry or information-seeking dialogues, ${ }^{4}$ but they do argue in other circumstances that will be described.

In what follows, I will use the word "argumentation" to designate any reason-based method for contending with disagreements, and the expression "persuasive argumentation" for reasoning specifically aimed at the resolution of disagreements through rational persuasion.

This paper proceeds as follows: I will begin, in section 2, by characterizing persistent disagreement as the type of disagreement that is usually resistant to persuasive resolution and will distinguish four different categories. In section 3, I will argue that persuasive argumentation is, at least on paper, a good instrument for overcoming disagreements (including the persistent case) since it gives us epistemic advantages. This will be contrasted in section 4, where I will consider that - under certain circumstances-opting for persuasive argumentation is a bad idea. In section 5, I will sketch different dialogical solutions for persistent disagreements, partly following the dialogue types developed by Walton and Krabbe (1995). In section 6, I will present a general pluralisticdynamic model for overcoming persistent disagreements and anticipate some objections. Finally, I will offer some concluding remarks.

\footnotetext{
${ }^{3}$ For these authors, an internal process of decision making is not based upon reasons but rather, upon inferences that work as inferential "modules." Reasons, then, are used when we want to do things like convince others, justify our actions, accuse others, report some information, deliberate, and so on (Mercier and Sperber 2017).

4 Note that Walton labels dialogue types, such as inquiry, deliberation, or information seeking dialogue where there can but need not be a disagreement, as "argumentative" dialogue types (1998). My pluralistic approach is more limited since it includes only cases where there happens to be a disagreement of some sort.
} 


\section{Persistent disagreement}

For the purpose of this paper, a disagreement can be defined as a dialogical and externalized clash of commitments between two or more parties.

The fact that the disagreement is dialogical means that it takes place within a dialogue. Externalized refers to the fact that it does not come into being until the parties express their clashing points of view. Therefore, two parties might hold opposing views regarding an issue, but unless they express it in a dialogue, we would not say that they disagree. When I say externalized, I am alluding to the principle of externalization (van Eemeren and Grootendorst 1984).

The fact that the disagreement is about commitments implies a clash regarding only propositions that the parties are publicly committed to. It refers to the concept of commitment as Walton and Krabbe (1995) use it, which derives from Hamblin (1970). It means that the parties clash regarding propositions that they are committed to defending, which does not always coincide with what they believe. ${ }^{5}$

Disagreements, then, will be persistent if it is unlikely that the parties have the means to resolve them by persuasive argumentation. This could happen in, at least, the following situations:

\subsection{Deep disagreement}

A related concept that has been subject to a lot of discussion is deep disagreement (Fogelin 1985). What is a deep disagreement? Fogelin considers that argumentation ${ }^{6}$ can only occur if there exists between the parties a context of "broadly shared beliefs and

\footnotetext{
${ }^{5}$ For Hamblin, in a dialogical system, the parties put forward statements representing their commitments, thus forming a commitment store: "The store represents a kind of persona of beliefs: it need not correspond with his real beliefs, but will operate, in general, approximately as if it did" (1970, p. 257). Hamblin does not specify cases where commitments and beliefs do not match, but we can think of a few examples: in the case of advocacy, a party might defend a standpoint without really believing it. Conversely, a party may hold a belief without considering it worthwhile to defend it.

${ }^{6}$ By "argumentation" Fogelin refers to what I have been calling "persuasive argumentation."
} 
preferences" (p. 6), which includes shared procedures for resolving disagreements. In such contexts, argumentation is normal, and the parties can reasonably expect to resolve their disagreement by rational persuasion.

However, sometimes the parties do not share the relevant background necessary for the resolution of disagreements. If that is the case, the parties face a deep disagreement. Deep disagreements are "immune to appeals to facts" and tend to "persist even when normal criticisms have been answered" (Fogelin 1985, p. 5). They are persistent since they do not refer only to isolated propositions "but instead [to] a whole system of mutually supporting propositions (and paradigms, models, styles of acting and thinking) that constitute, if I may use the phrase, a form of life" (p. 5). In other words, "we get a deep disagreement when the argument is generated by a clash of framework propositions" (p. 8). The disagreement, then, rests on propositions that are fundamental to the fabric of the parties' beliefs (Quine 1951). But Fogelin's diagnosis goes beyond mere implausibility; he claims that "deep disagreements cannot be resolved through the use of argument, for they undercut the conditions essential to arguing" (p. 8). Therefore these disagreements are just "not subject to rational resolution" (p. 11).

There has been much discussion of this topic. Some authors argue that it is unclear whether deep disagreements exist at all (Siegel 2013); some argue that even if they exist, it is usually not possible for the parties to realize their existence (Adams 2005), while others claim that even if they exist, a rational resolution is still available (Feldman 2005).

I do not pretend here to address these problems but, rather, present a very modest conclusion: at the very least, deep disagreements challenge the idea that we can resolve all disagreements by persuasive argumentation. In other words, "argument then ceases to be a tool for the rational resolution of disagreement; one of the primary functions of argument is undermined in such contexts" (Turner and Wright 2005, p. 27). However, according to Fogelin, even if deep disagreements exist, they are probably exceptional (1985, p. 9). Nevertheless, the situation is not so exceptional if we consider that a similar challenge exists in other cases that are persistent but not deep because "a disagreement can be intense 
without being deep. A disagreement can also be unresolvable without being deep" (Fogelin 1985, p. 8). But which disagreements fall into this category? Fogelin continues: "I can argue myself blue in the face trying to convince you of something without succeeding. The explanation might be that one of us is dense or pig-headed" (1985, p. 8). Fogelin seems to be thinking about cases in which the disagreement is not deep, but the parties are just not up to the task of resolving them. They are, in a way, suboptimal parties.

\subsection{Sub-optimal parties}

It is a common experience to feel that disagreement cannot be resolved because the counterpart is not able or prepared to see your point. The problem here lies not in the depth of the disagreement, but in the capabilities or willingness of the parties to resolve it. Some arguers are just not up to the task of presenting or acknowledging reasonable arguments, which makes those disagreements recalcitrant (Kloster 2018). Some people will discard arguments by falsely considering them personal attacks; some will disregard arguments based upon mere hatred for their counterpart; and others will be influenced by their confirmation bias, sticking to their guns even in light of significant amounts of evidence (Nickerson 1998). We are, more often than not, cognitive misers (Kahneman 2011), so it is no wonder that many disagreements are persistent. Naturally, this category could be mixed with the one presented before: an anti-vaxxer, ${ }^{7}$ for example, seems to be someone who is both incapable of acknowledging cogent arguments and in a deep disagreement with biologists.

For argumentation theory, specifically in the pragma-dialectical tradition, this situation has been described as failing to satisfy the second-order conditions for critical discussion (van Eemeren, Grootendorst, Jacobs, and Jackson 1993). The second-order conditions refer to an "idealized set of attitudes and intentions." That these conditions have been satisfied implies that the parties "wish to resolve, and not merely to settle, the disagreement" (p. 31). But besides a lack of willingness, they might also be cognitively inca-

\footnotetext{
${ }^{7}$ Someone who claims that the vaccines cause autism.
} 
pable of resolving the issue due to their lack of "ability to express their opinions, to listen to the opinions of others, and to change their own opinions when these fail to survive critical examination" (p. 33).

Therefore, the reason disagreements are persistent might, for example, be that at least one of the parties does not want to admit when they are wrong, is unable to follow complex arguments, or is merely serving their hidden interests. ${ }^{8}$

But even if the disagreement is not deep and the parties are not sub-optimal, the disagreement might still be persistent if the context of the dialogue is sub-optimal.

\subsection{Sub-optimal contexts}

Some contexts hinder the possibilities for the parties to arrive at a resolution, even when they have good dispositions and abilities. A good example of this kind of case is what has been called epistemic injustice (Fricker 2007), which, when it is applied to argumentative practices, has been coined argumentative injustice by Bondy (2010). Argumentative injustice can be defined as the phenomenon of "attaching reduced or excessive credibility to the premises of an argument, or to the strength with which an argument's premises support its conclusion, due to an identity prejudice attaching to the arguer, in the minds of the audience" (Bondy 2010, p. 263). Accordingly, sometimes the circumstances of the dialogue make it the case that, even inadvertently, the parties will increase or decrease credibility to some arguments due to structural injustice. If that is the case, an argument that in other circumstances would have had an easy resolution could end up being persistent, for example, if one of the parties does not believe that their counterpart is telling the truth. ${ }^{9}$

\footnotetext{
${ }^{8}$ Zenker (2007) provides an extensive list of second order conditions, the nonfulfillment of which may provide explanatory reasons for the persistence of disagreements.

${ }^{9}$ In this case, the boundary between sub-optimal parties and sub-optimal context might be blurry. For example: if in a certain culture people tend to give less credibility to the testimony of women over men, a disagreement could end up being persistent because one of the parties does not believe an argument given by a woman. Is that a problem regarding the party or the context? This depends
} 
But many other circumstances can turn disagreements persistent. Time constraints in broadcasting media, for instance, put pressure on the parties involved that might hinder their chances to fully develop their arguments and resolve the disagreement (Jacobs 2003). The format of social media communication tends to be polarizing and favours the spread of emotional rather than rational content (Brady et al. 2017).

For the pragma-dialectical school, these circumstances are labelled as third-order conditions for critical discussion (van Eemeren et al. 1993) and describe enabling conditions in the social or political context. These conditions imply that the parties "must be enabled to claim the rights and responsibilities associated with the argumentative roles defined by the model"10 (p. 33). Therefore, to put forward standpoints and criticize them, a party needs to "have the right to advance his or her view to the best of his or her ability" (p. 33). This right can be infringed upon in many ways. Besides the cases just presented, in a certain context there might be, for example, taboo topics, authority relationships between the parties, or dogmatic issues.

\subsection{Other cases}

We might still think about disagreements that are persistent and do not fall into any of the categories presented above: shallow moral disagreements, disagreements over taste, disagreements over policies or future events, predictions, and so on. Case 1.B. is a good example of this kind.

Considering these different types of persistent disagreements, in some cases, the parties might try to overcome their disagreement through other means - for example, by shifting the dialogue to a negotiation (van Laar and Krabbe 2018). However, there still are pretty good reasons for sticking to persuasive argumentation.

on how internalized the practice of giving less credibility to women is in that society.

10 "The model" refers to critical discussion, which is an ideal dialectical model in which "the parties attempt to reach agreement about the acceptability of the standpoints at issue by finding out whether these standpoints are tenable against doubt and other criticism, given the mutually accepted starting points" (Van Eemeren et al. 2014, p. 528). 


\section{Why argue?}

Argumentation and disagreement are deeply intertwined. On the one hand, we typically cannot explain the need to argue if there is not an existing disagreement ${ }^{11}$; on the other hand, when trying to overcome disagreement, persuasive argumentation seems to be the standard and preferred device (even in the persistent case), and there are good reasons for that.

The relationship between disagreement and argumentation can be easily traced in the literature. Jacobs and Jackson point out that "arguments are disagreement relevant speech events; they are characterized by the projection, avoidance, production or resolution of disagreement" (1980, p. 254). For Walton, as we saw, an argument is defined as "a social and verbal means of trying to resolve or at least contend with a conflict or difference that has arisen between two parties engaged in a dialogue" (1990, p. 411). Van Eemeren and Grootendorst consider that "argumentation is adduced in reaction to, or in anticipation of, a difference of opinion, and serves a role in the regulation of disagreement" (2004, p. 53).

But the fact that persuasive argumentation appears to be a proper response to disagreement does not imply that it is the only way in which we can manage disagreement successfully. There are many ways in which we can overcome a disagreement, and some of them are based on an exchange of reasons that cannot be reduced to persuasive argumentation. Consider the following example:

\section{Example 2: Dinner night}

Jack and Leyla want to go to a restaurant but disagree on whether to pick "The Rose Garden" or "Chez Martin." To overcome the disagreement, they have at their disposal, at least, the following means:

\footnotetext{
${ }^{11}$ Some authors, though, claim that argumentation can still exist without disagreement (Doury 2012; Micheli 2012). I do not deny that fact, but in this paper, I am focusing on cases where a disagreement does exist.
} 
2.1. Provide persuasive arguments for why one restaurant is a better choice than the other (food quality, price, location, etc.).

2.2. Negotiate a compromise: "We'll go to 'Chez Martin' this time and 'The Rose Garden' next time."

2.3. Toss a coin and let fate decide.

2.4. Call a friend and let them decide.

All these options seem reasonable, so is there a motive to prefer persuasive argumentation over the rest? There might be.

Jacobs (2003) considers argumentation to serve two main functions: a cognitive or epistemic function and a social function. The cognitive or epistemic function implies an individual effort for belief management, and it has to do with arriving as close as possible to the truth of the matter. If we define argumentation solely by that function, we should say that argumentation is something like "a social quest for true belief and error avoidance" (Goldman 1994, p. 28). ${ }^{12}$ But that is not the only function of argumentation.

The social function implies a quest for disagreement management; therefore, it has to do, among other things, with arriving at an agreement or, at least, some understanding.

In the non-persistent case, these functions typically go together: I can resolve the disagreement with good arguments, which will allow the parties to agree on a solution (see Example 1A). Since that solution has been backed by reasons, the chances of it being close to the truth ${ }^{13}$ are higher than, let us say, the result of tossing a coin.

\footnotetext{
12 Also see Biro and Siegel (2006); Goldman (2003); Lumer (2005).

13 It could be argued that argumentation is not always related to truth or knowledge and does not always have an epistemic or cognitive value. In practical argumentation, for instance, parties disagree about what to do, not about what is truth. However, even in those cases, arguments can be reconstructed from an epistemological point of view: "practical arguments, like other arguments, are to guide the addressee to cognize the (epistemic) acceptability of the thesis" (Lumer, 2005, p. 233). That is also true for ordinary language. It makes sense to say things like: "you do not know what you are doing" or "it is true that this is the best course of action." In this paper, I do not want to take a strong position about the epistemic value of practical and other kinds of disagreements,
} 
But when facing persistent disagreements, the parties will typically need to make a trade-off, and they should ask themselves: what is more important to me, truth or agreement? If they consider truth to be the more important value, they might insist on trying to persuade their counterpart to fulfil their epistemic goal, even at the expense of arriving at an agreement. If they consider the social aspect of agreement to be more important or urgent, they might look for other strategies, such as mediation or negotiation.

Another way of looking at this point is to consider the difference between belief and commitment. When we argue, we defend certain commitments that are normally (but need not be) aligned with our beliefs. Therefore, when we trade truth for agreement, we are also (normally) trading such a belief-based commitment for a commitment that is disconnected from that belief. For example, if I try to persuade my partner to go to a certain restaurant, it is because I believe that such a restaurant is the best option for us, and I have a belief-based commitment to defend that position. ${ }^{14}$ But if I cannot persuade her and we decide to toss a coin, I will still believe in the superiority of my preferred option, but I will be committed to following whatever option the coin dictates. Thus, while my beliefs are intact, my commitments have changed.

Persuasive argumentation, then, is an attempt to hit the social and epistemic optimum: if we manage to persuade, we will arrive at a solution that fulfils both the epistemic and the social function-that is, the parties arrive at an agreement while believing that the solution at which they arrived is true ${ }^{15}$ : their commitments are aligned with their beliefs.

In Example 2, 2.1 represents such an optimum. If one of the parties manages to persuade the other, they will both agree on the solution that seems closest to the truth of the matter, which could be something like "choosing the best restaurant in town for us."

but only say that it does make sense to use some meaning of the words "truth" or "epistemic."

14 With some exceptions, such as advocacy. For example, as a lawyer in a criminal trial, I might believe that my client is guilty, and yet be committed to defend his innocence.

${ }^{15}$ Of course, the solution could end up being false, but both parties are convinced that it is true. 
However, even if Jack is completely sure that "The Rose Garden" is the best restaurant in town, he might be willing to sacrifice his epistemic goal to fulfil his social goal. That will happen if reaching an agreement is more important to him than what (he thinks) is true. In this case, he might choose one of the other alternatives to maximize the social function by sacrificing, to a certain extent, the epistemic function.

In the end, it could happen that after the trade-off, the parties get closer to the truth, but each one of them sacrificed their epistemic goal. For instance, if after a disagreement A and B decide to flip a coin, and the coin favours A's position, which in the end happens to be the true answer, the parties would have come closer to the truth, but B would have traded their epistemic goal nevertheless (that is, their idea of what the true answer was).

But, if persuasive argumentation is such an optimum, why give it up? Would it not be advisable to always aim for it? I will address that concern in the following section.

\section{Why not argue?}

There is some skepticism regarding the idea that disagreements can be resolved by persuasive argumentation. This skepticism has been specifically directed to the idea that argumentation as rational persuasion is a useful tool for overcoming disagreements. In other words, we can say that, sometimes, persuasive argumentation is ineffective at achieving the social goal.

Some authors have objected that no evidence has ever shown that people actually reach a resolution when they argue (Goodwin 2007). Others think that some arguments can "backfire" (Cohen 2005). That is, an argument that is incapable of persuading a counterpart of a certain conclusion does not only leave the counterpart where they were before but in a worse position. Paglieri (2009) claims that - under some circumstances - the level of disagreement between the parties escalates because of the argumentative practice not despite it.

On the same note, Paglieri and Castelfranchi (2010) analyze the costs and dangers of (persuasively) arguing. They claim that the main reason why we should refrain from arguing in some circum- 
stances is strategic: "we do not engage in argument when doing so is likely to have an overall negative outcome" (p. 71). A negative outcome can arise from the costs or dangers of arguing. The costs can be direct costs (time, social exposure, cognitive resources, etc.) and opportunity costs (that is, things I could have done instead of arguing). The dangers refer to negative outcomes produced by the act of arguing: escalation of disagreement, deterioration of emotional well-being and personal relationships, among others.

In conclusion, there are many circumstances in which engaging in persuasive argumentation is a bad idea. To argue might not only be useless when facing persistent disagreement, but also arguments might backfire, disagreements might escalate, relationships might suffer stress, and we might just be wasting time and resources that could be of better use elsewhere.

Therefore, when faced with persistent disagreement, if we want to avoid persuasive argumentation for the reasons mentioned, is there anything else we could do to overcome those disagreements? Yes: "there are many ways of skinning a cat and arguing is just one of them" (Paglieri and Castelfranchi 2010, p. 74).

\section{Argumentative strategies for overcoming disagreements}

When facing a disagreement, the parties can ignore the issue or do something about it. And if they do something about it, they can use dialogical or non-dialogical strategies. Dialogical strategies revolve around the use of reasons in a dialogical context. Therefore, trying to persuade or to negotiate is a dialogical strategy, while hitting someone is non-dialogical. Dialogical strategies can be reason-based or non-reason-based. Along with rational persuasion, the parties can use means that most people would call irrational, like manipulation or coercion (Nettel and Roque 2012). I will call those strategies that are dialectical and rational "argumentative strategies" and those that are non-dialogical or not rational "non-argumentative strategies."

Here, I explore the conceptual hypothesis that argumentative strategies are dialogical attempts to overcome disagreements. But when can we say that an attempt is successful? It is useful to recall 
here the distinction between epistemic and social goals of argumentation.

We would say that the social goal has been fulfilled when the parties, who used to disagree on an issue, now agree on that same issue. A way to do this is, naturally, to rationally persuade and arrive at a resolution, but that is not the only way. If, for instance, when facing a persistent disagreement, two parties decide, on the basis of reasons, to toss a coin to decide, we would also say that they have agreed on a solution. Therefore, negotiating, tossing coins, and calling arbitrators are all means to fulfil the social goal of argumentation, and they are argumentative if the parties arrive at such solutions by providing reasons.

We would say that the epistemic goal has been at least partially fulfilled if the parties put forth their best efforts to arrive at their best estimate of the truth of the matter and agree on carrying out the proposed solution. Of course, that would be the case when the parties resolve their disagreement through persuasion but would also be the case when they use other overcoming strategies. For example, in a negotiation, one of the parties thinks that the solution is " 100 " while the other thinks it's " 0. " If they negotiate, they will split the difference and accept, for instance, "50," thus fulfilling half of their epistemic goal. But since it is not possible for both of them to completely fulfil their epistemic goals, we could say that they have overcome their disagreement if they accept the outcome. But even beyond that case, if, for instance, the same parties decide to externalize the solution through an arbitrator, and the arbitrator rules that the solution is " 100 ," we can say that the epistemic goal was also partially fulfilled if both parties accept that outcome. To fulfil an epistemic goal, epistemically limited agents may aspire to their epistemic goals partially, as when compromising or deferring to a third party. ${ }^{16}$

\footnotetext{
${ }^{16}$ By epistemic limitations I mean not only those limitations given by our cognitive incapacity to know the truth, but also our ability to account for the knowledge of others and persuade and be persuaded by them. In that sense, this approach is close to a social epistemological standpoint (Goldman and O’Connor 2019).
} 
Overcoming a disagreement will occur, then, when the parties to a disagreement agree, based on an exchange of reasons, on a method for totally fulfilling their social goal and, to a greater possible extent, fulfilling their epistemic goal. At this point, I can identify four methods for trying to overcome disagreements: persuasion dialogue, deliberation dialogue, negotiation dialogue, or settlement dialogue. I will call these ways of overcoming disagreements argumentative strategies, and-except for settlement dialogue - they are based on Walton and Krabbe's dialogue types (1995).

In the following sub-sections, I will consider only ways in which these strategies are used to overcome persistent disagreements, which does not mean that they cannot also be used to overcome non-persistent disagreements, or even used in cases when there is no disagreement at all.

\subsection{Persuasion dialogue}

Even though there are reasons to avoid persuasive argumentation to overcome persistent disagreements (see section 4, supra), persuasive argumentation is still useful and necessary in some cases. If that is the case, the parties will choose a persuasion dialogue. In this type of dialogue, the initial situation is a conflict of points of view, and the goal of the parties is to resolve the conflict by verbal means (Walton \& Krabbe, 1995, p. 68). Overcoming a disagreement by rationally persuading the counterpart implies, then, hitting the social and epistemic optimum.

When is persuasion dialogue unavoidable? There are at least two cases: first, the disagreement might have to do with what the parties "believe" rather than with a course of action. In that case, solutions like negotiation or compromise do not seem to be at hand. Nobody can change our minds by "offering" us something but can do so only by convincing us that their standpoint is correct. ${ }^{17}$

${ }^{17}$ Which is what makes the following joke, attributed to the Marx brothers, funny: "these are my principles, if you don't like them I have others." We think that principles are not something that can be traded or negotiated. In a dialogue, we would only be persuaded to change our principles if the counterpart convinces us that they are wrong. 
Second, one of the parties might be so certain about their view that they are not willing to sacrifice (not even partially) their epistemic goal, even if the issue is of a practical nature. Consider the following case:

\section{Example 3: Forest walk}

Rosa and Lilian are walking through the forest when they get lost at a crossroad. Rosa argues that they should go left, Lilian that they should go right:

(1)Rosa: I know this forest; we should take the right path.

(2)Lilian: I disagree. The left path goes north, which is where we are going.

(3)R: You are wrong, the left path goes to the river.

(4)L: Ok, let's do something, let's flip a coin to decide.

(5)R: No way, I'm totally sure we need to take the right path.

In this case, the parties will, presumably, keep trying to persuade each other. But how would persuasion look in a persistent situation? The four types of persistent disagreements presented in section 2 can help us shed light on this issue.

\subsubsection{Deep disagreement}

According to Fogelin, deep disagreements "by their nature, are not subject to rational resolution" (1985, p. 11). So what would resolution of a deep disagreement look like? Godden and Brenner (2010) provide a good approach: in cases of deep disagreement, they say, the parties understand fundamental concepts differently. Therefore, using those concepts as a framework for persuading others is useless. In other words, since the parties clash regarding framework propositions, those same propositions cannot be taken as common ground when arguing. What the parties should aim for instead is the transformation of those concepts. That transformation can be achieved, but it is "dialectical rather than demonstrative, amorphous rather than uniform, indeterminate rather than binary, it is neither fraudulent nor relativistic nor arbitrary" (p. 77). Resolution of deep disagreements should be, then, a long nonlinear and holistic process in which people slowly change their 
minds regarding an issue just as people, over time, change their views on politics or religion. It is difficult, but not impossible, to achieve.

\subsubsection{Sub-optimal parties}

If the problem lies in the sub-optimality of the parties, then we can aim for the improvement of the sub-optimal situation. If a party does not have the ability or the will to produce or acknowledge cogent arguments, the counterpart should try to modify that situation. But, as in the case of deep disagreement, straightforward argumentation regarding the topic of disagreement might not be the best approach. What else can we do?

Gilbert presents an interesting proposal in his concept of "coalescent argumentation" (1995; 1997), which he defines as "the implementation of methods and techniques that increase the heuristic element and decrease the eristic element while at the same time maintaining a realistic attitude to the essentially goal-oriented nature of most argumentation" (1997, p. 107). The heuristic element implies openness and willingness from the parties to change their minds, while the eristic element implies confrontation and competition. In coalescent argumentation, then, arguers use a multi-modal approach that includes not only logico-rational arguments but also emotional, visceral, and kisceral (intuitive) ones. To be successful, then, arguers should be empathic and try to understand where the counterpart is coming from (their position). Then, they should use multimodal argumentation to build mutual understanding and, ultimately, change the way in which they approach the situation.

Another interesting solution for these cases is given by Kloster (2018). She defines recalcitrant disagreements as disagreements that, without necessarily being deep, are difficult to resolve "because real reasoners have difficulty making full or accurate use of the rational resolution resources which are available to them" ( $p$. 3 ). For her, most of that difficulty can be explained by a lack of mutual trust. Trust, then, is a "measure of affective and social obstacles to reason" (p. 7).

She proposes that the parties of disagreement should build trust among each other. That is, they should consider not merely the 
logical and rational dimension but also "the affective, procedural, and social dimensions of disagreement" (p. 17). By building trust, the parties might be on the path to changing their sub-optimal attitude towards each other and the disagreement.

In summary, resolution in these cases could be achieved through cooperative (rather than adversarial) activity that includes multimodal techniques.

\subsubsection{Sub-optimal context}

If the persistence of disagreement arises from the context of a dialogue, an intuitive solution would be to modify such context. But modifying a sub-optimal context is not always possible. The problem of authority is a good example. If one of the parties is an authority with respect to the other, a disagreement that under other circumstances could be non-persistent might become persistent. ${ }^{18}$ But changing that relationship might not be possible. What to do then? The parties are the ones who need to be extremely vigilant. For example, in the case of disagreement between a boss and an employee, the boss should be careful to listen charitably to the opinions of their employee.

A similar problem arises in cases of argumentative injustice. Despite the best efforts of the parties, the injustice of the situation might be difficult to eliminate. For Bondy, then, the solution is the use of metadistrust - that is, "self-doubt regarding our credibility judgements" (Bondy 2010, p. 272). In other words, the parties should doubt their standpoints and try to develop a solution in a cooperative manner. Thus, when doubting our own standpoints, a persistent disagreement might prove to be resolvable after all.

\subsubsection{Other cases of persistence}

Since this category is a ragbag of different cases, it is expected that the ways in which parties might persuade each other might also vary.

Practical disagreements, which refer to the desirability of states of affairs (Lumer 2005), are usually linked to moral evaluation. In

\footnotetext{
${ }^{18}$ Lack of authority relationships is one of the $3^{\text {rd }}$ order conditions for critical discussion (Zenker 2007).
} 
such cases, a cooperative instead of an adversarial approach seems to be a good idea. Therefore, more than looking to win the argument, the parties should accept that there is no perfect solution for their common problem and look for a cooperative solution.

At least in some cases, disagreements over taste should not even be considered disagreements since the parties talk past each other by giving their own preferences (Sundell 2011). However, in other cases, it might be the case that the parties do hold clashing commitments regarding esthetic evaluation, for example, a disagreement regarding the beauty of a painting by Van Gogh versus the drawing of my daughter. If that is the case, one of the parties might hold a standard that turns them into a sub-optimal party (they do not really know about art history), which calls for the kind of approach described in section 5.1.2.

Disagreement about moral issues, which seems to be structurally different from disagreement about taste (Stojanovic 2019), can also fall under the categories described before. But in the case of shallow moral disagreements, persistence might not be attributed to the categories just described. So how can the parties persuade each other in such situations? It is difficult to tell, but, presumably, they should understand the root of their disagreement and see if an empathic and cooperative approach is feasible.

Another scenario that falls into this category is lack of information. For example, two paleontologists might disagree persistently over the faith of the Neandertals (Elgin 2010). If the paleontologists had the proper information, they should be able to resolve the disagreement, but under their current circumstances, the disagreement remains persistent. In such cases, and following Feldman (2006), it is probably advisable to suspend judgement.

Summarizing this sub-section, persuasion dialogue is still necessary in some circumstances and could lead to resolution of a persistent disagreement if the parties take a more cooperative and less adversarial approach.

\subsection{Deliberation dialogue}

Another dialogue type that can be used as a strategy for overcoming persistent disagreements is deliberation dialogue. Deliberation can be defined as "a type of dialogue in which a group of agents 
collaborates to make a decision about what course of action to take" (Walton 2006, p. 181). In deliberation, the parties analyze the pros and cons of certain decisions. Therefore, rather than trying to persuade each other (as in a persuasion dialogue) or making offers (as in a negotiation dialogue), they will typically make proposals regarding the best course of action (Ihnen Jory, 2016).

Walton and Krabbe (1995) suggest that the initial situation of deliberation is an open problem - that is, the parties have a decision to make together, and they argue cooperatively to find a solution. At first glance, then, it appears that deliberations are not suited to overcoming persistent disagreements. As shown before (section 2 supra), in a persistent disagreement the parties hold clashing commitments, whereas in a deliberation they do not since the problem is still open. ${ }^{19}$

However, it could happen that, realizing the persistence of the disagreement, the parties are willing to provisionally suspend judgement over the issue and then start deliberating. ${ }^{20}$ Consider the following example:

\section{Example 4: Risky business}

Bob and Joe own a construction company. A client asks them to construct a building. Bob argues that it is a bad idea

\footnotetext{
${ }^{19}$ According to Lewiński (2017), however, we can also understand deliberation as a role-based exchange of reasons. In such cases, the parties do hold clashing commitments for which they advocate during the deliberation process; thus, deliberation does not only occur when there is an open problem but also when there is a practical disagreement. These commitments can have a strong, neutral, or weak illocutionary force. If the parties hold weak commitments, they will only make tentative "suggestions" (or "proposals" to use Ihnen Jory's terminology). But if they hold neutral or strong commitments, they will defend their standpoint during the process. Accordingly, a deliberation dialogue in which the parties defend a strong or neutral commitment looks a lot like a persuasion dialogue, and, in fact "It might be hard to say where deliberation (as opposed to persuasion or negotiation dialogues) starts and ends" (Lewiński 2017, p. 106). As I will argue in the following section, such confusion of dialogue types is not problematic for the main argument of this paper, but quite the opposite.

${ }^{20}$ Or, in Lewiński's (2017) model, the parties do not even need to suspend their judgement but merely take advocacy roles for or against the courses of action suggested.
} 
to take that job since they are overbooked, and they risk losing part of their reputation if they do not deliver on time. Joe argues that they should take it because they have managed to handle this much work before, and this contract could secure incomes for the next year. After they reach a stalemate, the following dialogue ensues:

(1)Joe: Ok, let's hold back. We need to find a way to solve this.

(2)Bob: That's right. I propose that we go back to the client and tell him that we accept only if he offers $\$ 1$ million and gives us three more months.

(3)Joe: Ok! That would do it. What if he refuses?

(4)Bob: We'll see what to do then.

In the example above, the parties do not keep trying to persuade each other. Instead, they put their standpoints on hold in (1), turning the disagreement into an open problem. After that, Bob makes a proposal in (2) that Joe accepts in (3). In other words, they broaden the scope of possible options by considering why their earlier standpoints put them in a deadlock situation.

This type of deliberation differs from persuasion dialogue in that it requires the provisional suspension of standpoints. It also differs from negotiation regarding the type of speech act that the parties use: proposal vs offer (Ihnen Jory 2016). However, the difference between these three dialogical strategies seems to be blurry, and someone could consider Example 4 to be a case of persuasion or negotiation dialogue. But this only reinforces the main thesis of this paper: since it is difficult to tell when a dialogue type begins and another ends, it makes sense to call all these processes argumentation.

If the parties succeed in reaching agreement after deliberation, we can say that they have overcome their disagreement because they have used dialogical means to fulfil the social goal of argumentation (they now agree) while making their best effort to arrive at the truth of the matter. It could also happen that, in the end, the parties arrive at the conviction that the course of action chosen was the best one. If that is the case, some deliberation dialogues may 
help the participants, just like a successful persuasion dialogue, to realize a social end epistemic optimum.

\subsection{Negotiation dialogue}

Negotiation is a dialogue type where the parties begin with a conflict of interest and a need for cooperation, their main goal is to make a deal, and the parties aim at getting the best for themselves (Walton and Krabbe 1995, p. 72). This does not pertain only to conflicts of interest, but dialogues starting from differences of opinion might also be shifted to negotiation (van Laar and Krabbe 2018).

For a negotiation to work as a disagreement management strategy, the parties must be willing to trade truth for agreement. That is, they still think that the right answer is $\mathrm{P}$ or Q, but since they are not capable of persuading their counterpart, they are willing to settle for a middle-ground solution: keeping their beliefs, they lower the bar for their commitments. Consider the following example (Van Laar and Krabbe 2018):

\section{Example 5: Greenhouse emissions}

Party $A$ and Party $B$ disagree about the level of renewable energy that should be used by 2020. Party A proposes 18\% and party $B$ 14\%. After trying to persuade each other by providing several reasons, they arrive at a stalemate: no party has been able to persuade the other. Therefore, they decide to split the difference at $16 \%$.

In this case, the parties have arrived at a stalemate. Insisting on a persuasion dialogue seems like a bad idea. Deliberation is also an option if the parties provisionally suspend their judgement over the issue. But if they do not want to, they can still lower their expectations and seek a middle ground. That middle ground implies that they have traded truth for agreement: people in party A still believe that $18 \%$ is the right level, and people in party B still believe it is $14 \%$, but both are willing to split the difference.

But not every author looks favourably upon shifts to negotiation. For Godden and Casey (2020), shifting from persuasion to 
negotiation dialogue implies performing a fallacious move (in addition, it incentivizes rational hazards). Their criticism is directed towards shifts to negotiation, but since some of their arguments can also be applied to other types of shifts described in this paper, it makes sense to spend some time considering some of them.

One of the main claims that they make is that shifts to negotiation violate the principle of retrospective evaluation (Godden and Casey 2020, p. 7; see also Walton 1998, p. 201). This principle indicates that we need to evaluate contributions to the "shifted-to dialogue" (e.g., a negotiation dialogue) through the norms that were operative in the "shifted-from dialogue" (a persuasion dialogue). A move in the new dialogue will be illicit when it is detrimental to the realization of the main goal of the initial dialogue. According to Godden and Casey, the principle of retrospective evaluation applies to shifts from persuasion dialogue to negotiation dialogue in those cases where the outcome of the shifted-to dialogue, for example, a compromise agreement, is to fulfil the same function as the initially aspired outcome of the initial persuasion dialogue: namely, a resolution of the disagreement. As a result, when the parties shift from persuasion to negotiation and start making offers, they violate this principle and commit the fallacy of bargaining by "substituting offers for arguments" ( $\mathrm{p}$. 19).

For example, if Jack and Leyla's goals are to go to the best restaurant in town, and they cannot reach an agreement on which restaurant that is, then shifting to negotiation would be an illicit move. But if they just wanted to go to a restaurant, and they negotiate which restaurant they should go to, then for Godden and Casey the move is not illicit but redundant; the persuasion dialogue is a false start, and they should have started with a negotiation in the first place.

But once we consider both the social and epistemic functions of argumentation, these criticisms lose strength. There are three different cases to consider here, and in none of them do the parties seem to be committing a fallacy:

a) No shift to negotiation: If the parties' goals are to go to "the best" restaurant in town, they disagree persistently 
over it, and they refuse to change their original goal, then they will probably stick to their guns and avoid the shift. In other words, they consider that their epistemic goal is not worth sacrificing (so, no problem for Godden and Casey here).

b) Shift to negotiation: If both parties want to go to "the best" restaurant in town but arrive at a deadlock situation, they might consider a shift to negotiation. To do that, they need to change their original goals. Going to "the best" restaurant in town is not so important for them now, and they are willing to sacrifice part of their epistemic goal. In other words, the principle of retrospective evaluation does not preclude the parties from changing their original goals.

c) False start: If, finally, the parties discover that, more than wanting to go to the best restaurant in town, all they wanted was to go to a good enough restaurant, the move might not be redundant. The parties did not know in advance that the persuasion dialogue was not going anywhere so they needed to start to understand that it was reasonable to give up their epistemic goal.

In summary, if the negotiation succeeds, we can say that the parties have overcome the disagreement since the social goal would have been fulfilled, and the epistemic goal would have been fulfilled to the extent that the parties consider possible in the circumstances at hand.

\subsection{Settlement dialogue}

Besides engaging in persuasion, deliberation, or negotiation dialogue, there are many other things people usually do to overcome disagreements. There is mediation, arbitration, voting, civil court cases, and even coin-flipping. There is no specific name for dialogues in which the parties reason about those kinds of solutions, so I will call them settlement dialogues, and they are necessary when the parties conclude that there is no way to arrive at a consensus (cf. Woods 2004, p. 187)

Settlement dialogues may occur when the parties consider that their disagreement is persistent, but they realize that some shared 
arrangement is better than violence or definitive suspension of judgement. The initial situation, then, is disagreement, and the goal is to agree on a solution that is at least better than violence or no decision at all. ${ }^{21}$ A settlement dialogue can take many forms. It could imply voting, flipping a coin, or calling an arbitrator, mediator, or judge. The common feature of all of these solutions is that the parties reason about how to outsource the solution. Then, in a settlement dialogue, the parties trade truth for agreement by taking a chance. ${ }^{22}$ Outsourcing the solution implies that they could end up on the losing side, so the risk is greater than in negotiation where parties maintain control of the situation and split the difference.

It could be argued, however, that in some cases no reasons are given, so it is hard to qualify such solutions as argumentative according to the definition given in section 1. For example, if the parties flip a coin, that outsourcing of the decision is not argumentative in any way. That claim will be true in some cases, but in other cases, reasons are given, both at first order and metadialogical levels.

People use first-order reasons when they defend their standpoint. That happens in a settlement dialogue, for instance, if they give their arguments to a third party who acts as an arbitrator and the parties give their reasons to that arbitrator. In some voting processes, it is also common to provide reasons to back a vote (for example, in parliamentary debates). But reasons can also be given at the meta-dialogical level. In that case, the parties will be conducting meta dialogues or "dialogues about a dialogue" (Krabbe 2003). For instance, if the parties realize that they have reached a stalemate, they can say: "since there's no other way to decide, let's flip a coin," "let's ask my brother to decide for us because we are unable to," or "at this point we should vote because there's nothing left to do." In any case, they will be providing reasons at the first order or meta-dialogical level.

21 Especially if we consider that, in some practical situations, not making a decision implies making a decision (e.g., if my ex asks me out and I do not answer, that is a way of saying "no")

${ }^{22}$ With the exception, maybe, of mediation. That could be also considered as a kind of negotiation. 
But, if the risk of losing is greater, why would the parties prefer a settlement method over other methods like negotiation? Consider the following example:

\section{Example 6: Emergency room}

Philip and Rose are doctors who are performing a very complicated surgery when the patient starts having complications. The following dialogue ensues:

(1) Philip: We are losing him! We should give him 100 millimetres of drug $X$.

(2) Rose: I disagree! Drug Y would work better.

(3) P: We should call Doctor Jones, as he has more experience with this kind of complication.

(4) R: Ok then, let's call him. Whatever he says, I'm ok with it.

(5) P: Me too.

In this case, (1) and (2) represent an unsuccessful persuasion dialogue. But a negotiation would be odd; it does not make sense, for example, to give the patient both drugs or to offer money to settle the issue. But it does make sense to look for arbitration, which is a settlement method, so (3) and (4) are part of a settlement dialogue.

If a settlement dialogue is successful, the parties overcome their persistent disagreement since they have fulfilled the social goal while doing the best that they can to fulfil their epistemic goal. Sometimes, the best the parties can do is outsource the solution and take the chance of losing.

Summarizing this section, a persistent disagreement might be overcome by a variety of types of dialogues that represent a sort of toolbox. The limitations of persuasive argumentation could then be supplemented by other argumentative strategies, as long as the parties are willing to sacrifice part of their epistemic goal. 


\section{A dynamic pluralistic approach to argumentation}

The toolbox of argumentative solutions presented is a dynamic system. Aiming to overcome a disagreement, parties can try different argumentative strategies, shifting from one dialogue type to another and mixing them in the process. We can call this proposal a dynamic pluralistic approach to argumentation.

If the parties do not succeed in overcoming the disagreement, they can suspend judgement ${ }^{23}$ or look for non-dialogical or nonrational agreements (like, for instance, manipulation, violence or censorship). A possible model for how to deal with persistent disagreements using this approach is presented in Figure 1.

This flowchart is just one approach to a process that might take different shapes. ${ }^{24}$ Some parties could go straight for negotiation and look for a suspension if it does not work; others could use mixed dialogue types. However, the flowchart does show how a dynamic pluralistic approach works. The different strategies are ordered according to the extent to which the epistemic goal is or may be sacrificed. As we go down the chart, the parties sacrifice their epistemic goals more and more. So even if the solution is true after a settlement, if they are on the losing side, the decision will go against their initial epistemic goal.

Regarding this model, it could be argued that, in the end, there is continuity between the proposed solutions. Take Example 4, for instance. It is supposed to be a deliberation, but it could also be taken as a persuasion dialogue, where the parties agree on a new standpoint that was not their initial one. But it could also be seen as a negotiation; the parties simply split the difference and agree on a middle-ground solution. The same thing happens with Example 6; it is supposed to be a settlement dialogue, but it could also be seen as a persuasion, negotiation, or deliberation dialogue.

\footnotetext{
${ }^{23}$ When possible, as James (1960) points out, suspension of judgement is not feasible when facing a "forced option."

${ }^{24}$ Woods (2004) proposes a different model to overcome what he calls "standoffs of force 1 - 5" (cases that could be assimilated into persistent disagreements). Based on that model, depending on the circumstances of the disagreement, different strategies are advised.
} 


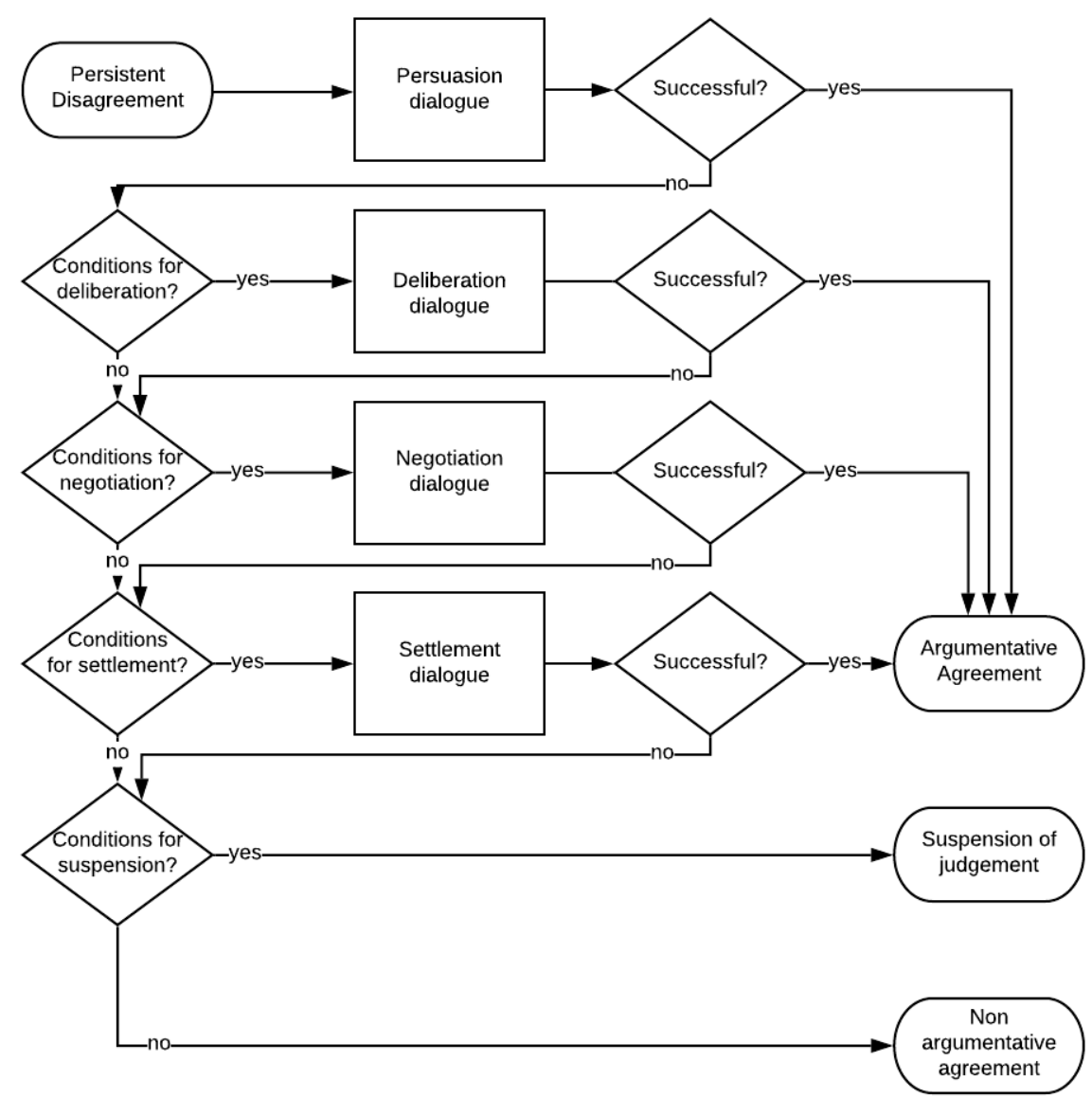

Figure 1: Flowchart of strategies for persistent disagreement

This criticism can be extended to the dialogue type theory as well. Dialogue types are often mixed (Walton and Krabbe 1995), and the parties are usually unable to understand in which dialogue type they are actually engaged (Goodwin 2007).

However, I do not see the problem of the "confusion of dialogue types" as an objection to the model I am presenting. Quite the opposite; if dialogical strategies to overcome persistent disagreements represent a sort of spectrum, then it makes even more sense to call the reasoning that takes place at every level of the spectrum argumentation. 


\section{Conclusions}

I aimed to present the problem of persistent disagreement as a challenge for argumentation theory that can be addressed in a cogent way through a dynamic and pluralistic approach. The introduction of the concept of "persistent disagreements" is the first step towards that goal, and I think it is clear enough thanks to the taxonomy of disagreements presented in section 2 . The arguments for and against persuasive argumentation serve a double purpose: they identify the advantages of persuasive argumentation and also its limits. The argumentative strategies presented in section 5 are intended to provide the arguers with more alternatives for overcoming disagreements, given the limitations of persuasive argumentation presented before. Finally, section 6 tries to put all the above strategies into a dynamic system represented by a flowchart and address some objections.

Several problems are yet to be resolved: I have not said anything about normative standards. That is important because it allows us to distinguish between rational and non-rational agreement. Can, for instance, a deliberation or settlement dialogue be unreasonable? Under which circumstances? Are those circumstances different for every dialogical strategy, as Walton and Krabbe (1995) claim? Are there common normative standards for all of them? What are the precise conditions for the use of dialogical strategies? When should we prefer one over the other? What are the requisites that every solution has? These questions should be addressed in future research.

Acknowledgements: Thanks to Jan Albert van Laar, Leah Henderson, Barteld Kooi, Constanza Ihnen Jory, Rodrigo Valenzuela and two anonymous reviewers for their helpful comments on earlier versions of this paper. I acknowledge support from the National Agency of Research and Development of Chile (ANID) and the University of Groningen.

\section{References}

Adams, D. M. 2005. Knowing when disagreements are deep. Informal Logic 25(1): 65-77. https://doi.org/10.22329/il.v25i1.1045 
Biro, J., and H. Siegel. 2006. In defense of the objective epistemic approach to argumentation. Informal Logic 26(1): 91-101. https://doi.org/10.22329/il.v26i1.432

Blair, J. A. 2012. Argumentation as rational persuasion. Argumentation, 26(1): 71-81. https://doi.org/10.1007/s10503-011-9235-6

Bondy, P. 2010. Argumentative injustice. Informal Logic 30(3): 263278. https://doi.org/10.22329/il.v30i3.3034

Brady, W. J., Wills, J. A., Jost, J. T., Tucker, J. A., Van Bavel, J. J., and S. T. Fiske. 2017. Emotion shapes the diffusion of moralized content in social networks. In Proceedings of the National Academy of Sciences of the United States of America. 7313-7318 https://doi.org/10.1073/pnas.1618923114

Cohen, D. H. 2005. Arguments that backfire. In The uses of argument: Proceedings of a conference at McMaster University, ed. D. Hitchcock, 58-65. https://scholar.uwindsor.ca/ossaarchive/OSSA6/papers/8/?utm_sourc $\mathrm{e}=$ scholar.uwindsor.ca $\% 2$ Fossaarchive $\% 2 \mathrm{FOSSA} 6 \% 2 \mathrm{Fpapers} \% 2 \mathrm{~F} 8$ \&utm_medium $=$ PDF\&utm_campaign $=$ PDFCoverPages

Doury, $\bar{M}$. 2012. Preaching to the converted. Why argue when everyone agrees? Argumentation 26(1): 99-114. https://doi.org/10.1007/s10503-011-9237-4

Elgin, C. Z. 2010. Persistent disagreement. In Disagreement, eds. R. Feldman and T. A. Warfield, 53-68. Oxford: Oxford University Press.

Eemeren, F. H. van, B. Garssen, E. C. W. Krabbe, A. F. Snoeck Henkemans, B. Verheij, and J. H. M. Wagemans. 2014. Handbook of argumentation theory. In Handbook of Argumentation Theory. https://doi.org/10.1007/978-90-481-9473-5

Eemeren, F. H. van and R. Grootendorst 1984. Speech acts in argumentative discussions: A theoretical model for analysis of discussions directed towards solving conflicts of opinion. Dordrecht, Holland: Foris Publications.

Eemeren, F. H. van and R. Grootendorst. 2004. A systematic theory of argumentation: The pragma-dialectical approach. Cambridge: Cambridge University Press.

Eemeren, F. H. van, R. Grootendorst, S. Jacobs, and S. Jackson. 1993. Reconstructing argumentative discourse. Tuscaloosa, Alabama: University of Alabama Press.

Feldman, R. 2005. Deep disagreement, rational resolutions, and critical thinking. Informal Logic 25(1), 12-23. https://doi.org/10.22329/i1.v25i1.1041

Feldman, R. 2006. Epistemological puzzles about disagreement. In 
Epistemology Futures, ed. S. Hetherington, 216-236. Oxford: Oxford University Press.

Fogelin, R. 1985. The logic of deep disagreements. Informal Logic 25(1): 3-11. https://doi.org/10.22329/il.v25i1.1040

Fricker, M. 2007. Epistemic injustice: Power and the ethics of knowing. Oxford: Oxford University Press.

Gilbert, M. 1995. Coalescent argumentation. Argumentation 9(5): 837852. https://doi.org/10.1007/BF00744761

Gilbert, M. 1997. Coalescent Argumentation. New York: Routledge.

Godden, D. and J. Casey. 2020. No place for compromise: resisting the shift to negotiation. Argumentation 34: 499-535. https://doi.org/10.1007/s10503-020-09517-z

Godden, D. M. and W. H. Brenner. 2010. Wittgenstein and the logic of deep disagreement Wittgenstein y la lógica del desacuerdo profundo. Cogency 2(2): 41-80.

Goldman, A. I. 1994. Argumentation and Social Epistemology. The Journal of Philosophy 91(1): 27-49. https://doi.org/10.22329/il.v23i1.2153

Goldman, A. I. 2003. An epistemological approach to argumentation. Informal Logic 23(1): 51-63. https://doi.org/10.22329/il.v23i1.2153

Goldman, A. and C. O'Connor. 2019. Social epistemology. In The Stanford Encyclopedia of Philosophy. URL accessed 5 November 2019:

$<$ https://plato.stanford.edu/archives/fall2019/entries/epistemologysocial/s.

Goodwin, J. 2007. Argument has no function. Informal Logic 27(1): 6990. https://doi.org/10.22329/il.v27i1.465

Govier, T. 1989. Critical thinking as argument analysis? Argumentation 3(2): 115-126. https://doi.org/10.1007/BF00128143

Hamblin, C. 1970. Fallacies. London: Meuthen.

Ihnen Jory, C. 2016. Negotiation and deliberation: Grasping the difference. Argumentation 30(2): 145-165. https://doi.org/10.1007/s10503-014-9343-1

Jacobs, S. and S. Jackson 1980. Structure of conversational argument: Pragmatic bases for the enthymeme. The Quarterly Journal of Speech 66: 251-265.

Jacobs, S. 2003. Two conceptions of openness in argumentation theory. In Proceedings of the Fifth Conference of the International Society for the Study of Argumentation, eds. F. H. van Eemeren, J. A. Blair, C. A. Willard, and A. F. Snoeck Henkemans, 553-556. SicSat.

James, W. 1960. The will to believe: And other essays in popular philosophy, and human immortality. New York: Dover Publications. 
Kahneman, D. 2011. Thinking fast, thinking slow. Tavistock, London: Interpretation.

Kloster, M. 2018. Another dimension to deep disagreements: Trust in argumentation. Topoi 1. https://doi.org/10.1007/s11245-018-9617-6

Krabbe, E. C. W. 2003. Metadialogues. In Proceedings of the Fifth Conference of the International Society for the Study of Argumentation, eds. F. H. van Eemeren, J. A. Blair, C. A. Willard, and A. F. Snoeck Henkemans, 641-644. Sicsat.

Laar, J. A. van and E. C. W. Krabbe. 2018. Splitting a difference of opinion: The shift to negotiation. Argumentation 32(3): 329-350. https://doi.org/10.1007/s10503-017-9445-7

Lewiński, M. 2017. Practical argumentation as reasoned advocacy. Informal Logic 37(2): 85-113. https://doi.org/10.22329/il.v37i2.4775

Lumer, C. 2005. The epistemological theory of argument- how and why? Informal Logic 25(3): 213-243. https://doi.org/10.22329/il.v25i3.1135

Mercier, H. and D. Sperber. 2011. Why do humans reason? Arguments for an argumentative theory. Behavioral and Brain Sciences 34(2): 57-74. https://doi.org/10.1017/S0140525X10000968

Mercier, H. and D. Sperber. (2017). The enigma of reason: A new theory of human understanding. Penguin Books.

Micheli, R. 2012. Arguing without trying to persuade? elements for a non-persuasive definition of argumentation. Argumentation 26(1): 115-126. https://doi.org/10.1007/s10503-011-9240-9

Nettel, A. L. and G. Roque. 2012. Persuasive argumentation versus manipulation. Argumentation 26(1): 55-69. https://doi.org/10.1007/s10503-011-9241-8

Nickerson, R. S. 1998. Confirmation bias: A ubiquitous phenomenon in many guises. Review of General Psychology 2(2):175-220. https://doi.org/10.1037/1089-2680.2.2.175

Paglieri, F. 2009. Ruinous arguments: Escalation of disagreement and the dangers of arguing. In Argument Cultures: Proceedings of OSSA 09, ed. J. Ritola, 1-15. Scholarship at UWindsor.

Paglieri, F. and C. Castelfranchi. 2010. Why argue? Towards a costbenefit analysis of argumentation. Argument and Computation 1(1): 71-91. https://doi.org/10.1080/19462160903494584

Quine, W. van O. 1951. Two dogmas of empiricism. Philosophical Review 60(1): 20-43.

Siegel, H. 2013. Argumentation and the epistemology of disagreement. In Proceedings of the Ontario Society for the Study of Argumentation Conference vol. 10, eds. D. Mohammed and M. Lewiński OSSA, 2226. 
http://scholar.uwindsor.ca/ossaarchive/OSSA10/papersandcommentar ies $/ 157$

Stojanovic, I. 2019. Disagreements about taste vs. disagreements about moral issues. American Philosophy Quarterly 56(1), 29-41.

Sundell, T. 2011. Disagreements about taste. Philosophical Studies: An International Journal for Philosophy in the Analytic Tradition, 155(2): 267-288. https://doi.org/10.1007/s1

Turner, D. and L. Wright. 2005. Revisiting deep disagreement. Informal Logic 25(1). https://doi.org/10.22329/il.v25i1.1042

Walton, D. N. 2006. How to make and defend a proposal in a deliberation dialogue. Artificial Intelligence and Law 14: 177-239. https://doi.org/10.1007/s10506-006-9025-x

Walton, D. N. 1990. What is reasoning? What is an argument? The Journal of Philosophy 87(8): 399-419. https://doi.org/10.2307/2026735

Walton, D. N. 1998. The New Dialectic: Conversational Contexts of Argument. Toronto: University of Toronto Press.

Walton, D. N. and E. C. W. Krabbe. 1995. Commitment in Dialogue: Basic Concepts of Interpersonal Reasoning. New York: State University of New York Press.

Woods, J. H. 2004. The Death of Argument: Fallacies in Agent Based Reasoning (Vol. 3). Dordrecht: Springer.

Zenker, F. 2007. Pragma-dialectic' s necessary conditions for a critical discussion. In Proceedings of the Ontario Society for the Study of Argumentation (OSSA) vol. 7. Scholarship at UWindsor. https://scholar.uwindsor.ca/cgi/viewcontent.cgi?article=1413\&contex $\mathrm{t}=$ ossaarchive 